\title{
SEISMIC TIME HISTORY ANALYSIS OF SIX STORY SHEAR BUILDING WITH NEWMARK- $\beta$ METHOD AND ETABS
}

\author{
Chetan Chhindam ${ }^{1}$, Pankaj Autade ${ }^{2}$ \\ ${ }^{l}$ PG Student, Dept of Civil Engineering, Dr. V.V.P. College of Engineering, M.S., India \\ ${ }^{2}$ Assistant Professor, Dept of Civil Engineering, Dr. V.V.P. College of Engineering, M.S., India
}

\begin{abstract}
Analysis of a six story shear building subjected to base ground motion excitation is shown in this study. The time history records of ground motion for Bhuj earthquake is used for understanding the response of the structural system. Modal analysis is performed using transformation of coordinates so that the MDOF system is analyzed like SDOF system. The dynamic equilibrium system of modal coordinates became an Eigen value problem and solved for characteristic equation. Newmark's Linear Acceleration Method is used as theoretical time stepping method for obtaining response of the MDOF system under base ground motion excitation. The stability condition was checked and observed that the Newmark's method can be satisfactorily used for this study. Step by step procedure of Newmark's $\beta$ Method is also elaborated showing equations that were used in the study to prepare computer algorithms. This study has made an attempt to compare the analytical results of theoretical time stepping method and ETABS computer software. The vibration mode shape vectors obtained from theoretical calculations are exactly matching mode shapes obtained from ETABS analysis by normalizing at top floor. The modal time periods of ETABS and theoretical calculations are in good conformity with each other. The story shear force results of theoretical analysis by Newmark's Method and by ETABS are showing variation of $2 \%$. Both the analyses have shown similar response pattern for floor displacement of the MDOF system under consideration with a variation of $3 \%$ for top story. Time history of top story displacement record obtained from Newmark's Method is similar to that of ETABS response time history.
\end{abstract}

Keywords: MDOF shear building, Modal Analysis, Time history analysis, Newmark- $\beta$ method, story displacement ****

\section{INTRODUCTION}

India has experienced some of the severe earthquake events in the last few decades that sought attention of the engineers and requirement of awareness and efforts to reduce damage.[1] The Indian subcontinent is prone to earthquakes due its tectonic setup. The seismic hazard is severe along the belts of Himalaya and Western region of India.[2] Some major earthquakes have occurred in this region is past decades and reason is associated with the collision and friction between Indian and Eurasian tectonic plates. Information on ground shaking magnitude and its occurring frequency is beneficial for proper assessment of the vulnerable region.[3] A suitable database of occurring ground shaking events collected at a platform for engineers to study is very much required. The strong motion instrumentation network of India provides such details required.[4] The ground motion data for the various earthquake events are also readily available by COSMOS[5]

Modal analysis[6][7] by transformation of coordinates is performed for the MDOF system to investigate the vibration shape vectors and modal time periods. The Newmark's Linear Acceleration Method has shown the response of structure subjected to base ground excitation.

\section{THEORETICAL ANALYSIS}

\subsection{Formation of Mathematical Model}

A multi-degree freedom system (MDOF) six story shear building with four columns per story at a grid size of $3 \mathrm{~m} \mathrm{x}$ $3 \mathrm{~m}$ having $4 \mathrm{~m}$ height of columns is subjected to horizontal translational ground motion at base. The size of columns is $400 \mathrm{~mm} \times 400 \mathrm{~mm}$ and floor is with slab thickness of $125 \mathrm{~mm}$. In order to perform mathematical analysis, the following assumptions are made to do idealization of building:

- The total mass of the structure is concentrated in the form of lumped mass at levels of all floors. The beams and floor systems are considered rigid.

- The motion of structure at all floors is predominantly lateral and in same direction to that of ground motion. The six story shear building will have six degrees of freedom in translation, one at each floor.

- The axial deformation and forces in beams and columns are neglected.

The fig. 1 represents mathematical idealization of six story shear building subjected to ground motion acceleration $\ddot{u}_{g}(t)$ with relative story displacement in terms of $u_{j}$, where $j$ is the number of floor. 


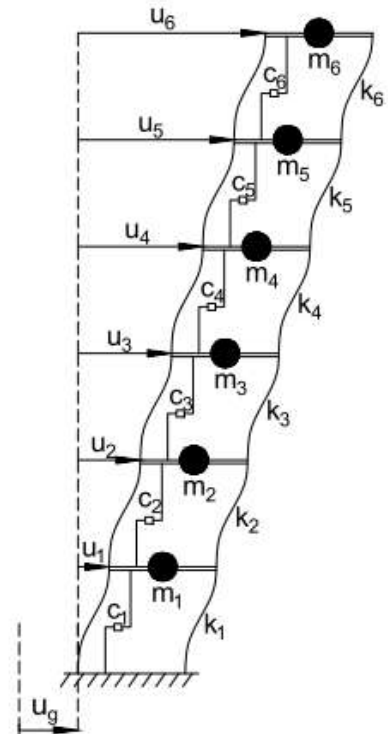

Fig-1: Single bay model of six story shear building

The dynamic equilibrium condition at time instance $t$, governing the linear response of MDOF system with $[M]$, $[C],[K]$ as the mass, damping and stiffness matrices, respectively, may be expressed in the form of coupled differential equation in matrix notation.

$$
[\mathrm{M}]\{\ddot{u}(t)\}+[\mathrm{C}]\{\dot{u}(t)\}+[K]\{u(t)\}=-[\mathrm{M}]\{1\} \ddot{u}_{g}(t)
$$

where $\{1\}$ represents the influence coefficient vector showing the motion of rigid body corresponding to unit displacement of ground motion. The coordinates of the equation (1) can be transformed in terms of modal matrix $[\Phi]$ and can be shown as,

$$
\{u(t)\}=[\Phi] q(t)
$$

The uncoupled differential equation using modal coordinates is now expressed as

$$
\begin{aligned}
& {[\mathrm{M}][\Phi]\{\ddot{q}(t)\}+[\mathrm{C}][\Phi]\{\dot{q}(t)\}+[K][\Phi]\{q(t)\}} \\
& =-[\mathrm{M}]\{1\} \ddot{u}_{g}(t)
\end{aligned}
$$

Normalizing the uncoupled equation (3) with respect mass matrix $[M]$, and expressing in terms of damping ratio $\xi$ and circular frequency $\omega$, the equation can now be written as

$$
\ddot{q}_{i}(t)+2 \xi \omega_{i} \dot{q}_{i}(t)+\omega_{i}^{2} q_{i}(t)=-\Gamma_{i} \ddot{u}_{g}(t)
$$

where $\Gamma_{i}$ is the modal participation factor and $i$ being the mode number and $j$ being the floor number.

$$
\Gamma_{i}=\frac{\left\{\Phi_{j i}\right\}^{T}[M]\{1\}}{\left\{\Phi_{j i}\right\}^{T}[M]\left\{\Phi_{j i}\right\}}
$$

\subsection{Mode Shapes and Time Periods}

To determine the vibration frequencies of the MDOF system, free vibration is considered with undamped condition. This leads to characteristic equation as follows:

$$
\left([K]-\omega^{2}[M]\right)\left\{\Phi_{j i}\right\}=0
$$

Thus transformation of coordinate makes the analysis of shear building as an eigen value problem having mode shape vector $\varphi_{i j}$. To obtain a non-trivial solution of equation (6), the determinant of the matrix $\left[K-\omega^{2} . M\right]$ is equaled to 0 .

$$
\left|\left\{[K]-\omega^{2}[M]\right\}\right|=0
$$

The formulation of mass and stiffness matrices are as follows:

$$
\begin{aligned}
M & =\left[\begin{array}{cccccc}
m_{1} & 0 & 0 & 0 & 0 & 0 \\
0 & m_{2} & 0 & 0 & 0 & 0 \\
0 & 0 & m_{3} & 0 & 0 & 0 \\
0 & 0 & 0 & m_{4} & 0 & 0 \\
0 & 0 & 0 & 0 & m_{5} & 0 \\
0 & 0 & 0 & 0 & 0 & m_{6}
\end{array}\right] \\
K & =\left[\begin{array}{cccccc}
k_{1}+k_{2} & -k_{2} & 0 & 0 & 0 & 0 \\
-k_{2} & k_{2}+k_{3} & -k_{3} & 0 & 0 & 0 \\
0 & -k_{3} & k_{3}+k_{4} & -k_{4} & 0 & 0 \\
0 & 0 & -k_{4} & k_{4}+k_{5} & -k_{5} & 0 \\
0 & 0 & 0 & -k_{5} & k_{5}+k_{6} & -k_{6} \\
0 & 0 & 0 & 0 & -k_{6} & k_{6}
\end{array}\right]
\end{aligned}
$$

The eigen values $\omega_{i}^{2}$ and corresponding vibration mode shapes $\varphi_{i j}$ are determined as shown in the fig. 2 and fig.3, respectively.

This is done by normalizing the modes such that the element corresponding to the $6^{\text {th }}$ story is unity. This makes the following equation (8) true with modes being mass orthonormal.

$$
\left\{\Phi_{i}\right\}^{T}[K]\left\{\Phi_{i}\right\}=\omega^{2}
$$

The modal time period $T_{i}$ of each mode are also obtained.

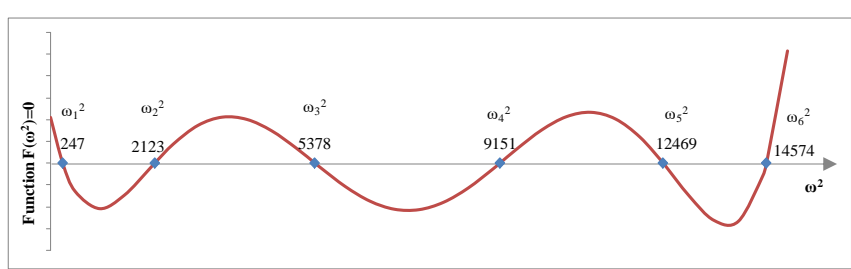

Fig-2: Variation of Determinant Function with $\omega^{2}$ 


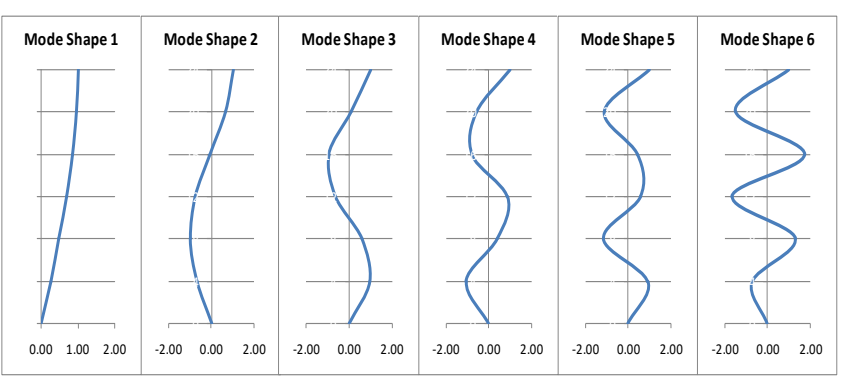

Fig-3: Modal Shapes of Vibration

The modes of vibration $i$ and $r$ are compared with each other when $\omega_{i} \neq \omega_{r}$ and are found to be satisfying the orthogonality conditions as shown in equation (9) and (10).

$$
\begin{aligned}
& \left\{\Phi_{i}\right\}^{T}[K]\left\{\Phi_{r}\right\}=0 \\
& \left\{\Phi_{i}\right\}^{T}[M]\left\{\Phi_{r}\right\}=0
\end{aligned}
$$

\subsection{Equivalent Static Method of Analysis}

The six story shear building is analyzed by Equivalent Static Method[8]. As this study is with respect to the Bhuj Earthquake time history record, Zone $\mathrm{V}$ is selected as per the Seismic Zoning Map of India[8]. The parameters for the seismic coefficient $A_{h}$ are considered as follows:

Zone Factor $Z=0.36$

Importance Factor $I=1$

Response Reduction Factor $R=3$

Soil Type $=1$

Time Period $T_{a}=0.813 \mathrm{sec}$

Response Acceleration Coefficient $S_{a} / g=1.23$

The seismic coefficient $A_{h}$ and seismic weight $W$ of the six story shear building gives the theoretical value of base shear $V_{B(T H)}$ for each mode. The theoretical value of story displacement of the building is calculated using this base shear.

\subsection{Time History Analysis by Newmark's Method}

The time history record for Ground Acceleration of Bhuj Earthquake - 26 January 2001 at a time interval $\Delta t$ of 0.005 seconds as shown in fig.4 is obtained from COSMOS Virtual Data Center[5] for Ahmedabad Station Component N78E.

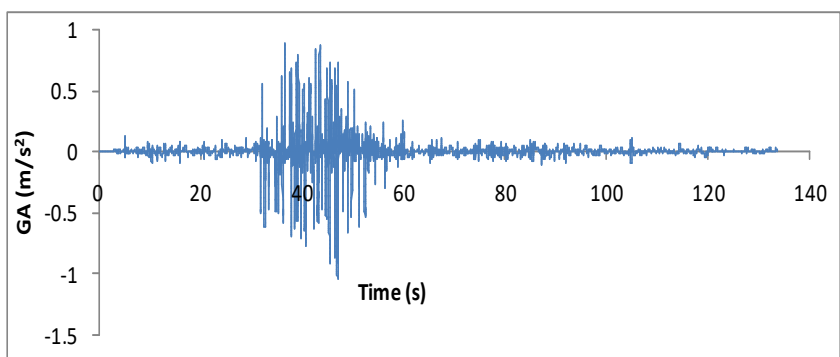

Fig-4: Time History Record of Bhuj Earthquake 26.01.2001
The Newmark's Linear Acceleration Method[9][10] is using as a theoretical time stepping method for this study. The ratio of time interval $\Delta t$ to the natural time period of vibration $T_{N}$ of the system satisfies the stability condition as shown in equation (11) and convergence condition as shown in equation (12) of the Newmark's method at $\beta=1 / 6$.

$$
\frac{\Delta t}{T_{N}} \leq 0.551
$$

$\frac{\Delta t}{T_{N}} \leq 0.389$

The algorithm parameters $\gamma$ and $\beta$ are selected as $1 / 2$ and $1 / 6$ respectively and additional system properties considered are $\hat{k}$ and $\Delta \hat{p}$. Considering initial values of relative velocity and relative displacement as zero, the time stepping operation is performed using Newmark's Method to obtain the relative acceleration $\ddot{q}$, relative velocity $\dot{q}$ and relative displacement $q$. The step by step procedure of Newmark's Method that was implemented on a computer program is listed hereafter in equation (13) to (25)

Initial Calculations:

$$
\begin{aligned}
& \ddot{q}_{0}=\frac{p_{0}-c_{i} \dot{q}_{0}-k_{i} q_{0}}{m_{i}} \\
& \hat{k}_{i}=k_{i}+\frac{\gamma}{\beta \Delta t} c_{i}+\frac{1}{\beta(\Delta t)^{2}} m_{i} \\
& a_{i}=\frac{1}{\beta \Delta t} m_{i}+\frac{\gamma}{\beta} c_{i} \\
& b_{i}=\frac{1}{2 \beta} m_{i}+\Delta t\left(\frac{\gamma}{2 \beta}-1\right) c_{i}
\end{aligned}
$$

Calculation for each time step, $n$ :

$$
\begin{aligned}
& p_{i(n)}=-\Gamma_{i} \ddot{u}_{g(n)} \\
& \Delta p_{i(n)}=p_{i(n+1)}-p_{i(n)} \\
& \Delta \hat{p}_{i(n)}=\Delta p_{i(n)}+a_{i} \dot{q}_{i(n)}+b \ddot{q}_{i(n)} \\
& \Delta q_{i(n)}=\frac{\Delta \hat{p}_{i(n)}}{\hat{k}_{i}} \\
& \Delta \dot{q}_{i(n)}=\frac{\gamma}{\beta \Delta t} \Delta q_{i(n)}-\frac{\gamma}{\beta} \dot{q}_{i(n)}+\Delta t\left(1-\frac{\gamma}{2 \beta}\right) \ddot{q}_{i(n)}
\end{aligned}
$$




$$
\begin{aligned}
& \Delta \ddot{q}_{i(n)}=\frac{1}{\beta(\Delta t)^{2}} \Delta q_{i(n)}-\frac{1}{\beta \Delta t} \dot{q}_{i(n)}-\frac{1}{2 \beta} \ddot{q}_{i(n)} \\
& q_{i(n+1)}=q_{i(n)}+\Delta q_{i(n)} \\
& \dot{q}_{i(n+1)}=\dot{q}_{i(n)}+\Delta \dot{q}_{i(n)} \\
& \ddot{q}_{i(n+1)}=\ddot{q}_{i(n)}+\Delta \ddot{q}_{i(n)}
\end{aligned}
$$

The result of entire time stepping operation further provides the peak deformation $D_{i}$ to identify the peak pseudo acceleration $A_{i}$ for each mode. The corresponding values of equivalent lateral forces $F_{j i}$ for each story are obtained using respective values of lateral force vector $s_{j i .}$

The story shear forces obtained from $F_{j i}$ for all modes are combined using the SRSS method[8]. Maximum response of each story in terms of displacement is recorded along with the time instance of peak response.

\section{BUILDING MODEL IN ETABS}

ETABS is the software tool used in this study for analysis of six story building system. The direction of analysis is restricted to X-Direction only so that the system represents a shear building with six translational degrees of freedom in $\mathrm{X}$-Direction only.

The six story building model prepared in ETABS is shown in fig. 5. The material and dimensions of the model are similar to the sizes considered for theoretical analysis. The time history loading is applied to model as shown in fig. 6

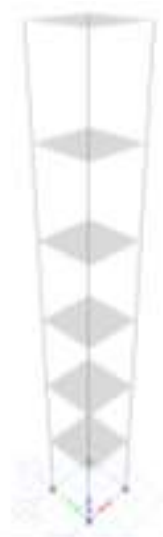

Fig-5: Six Story Shear Building Model in ETABS

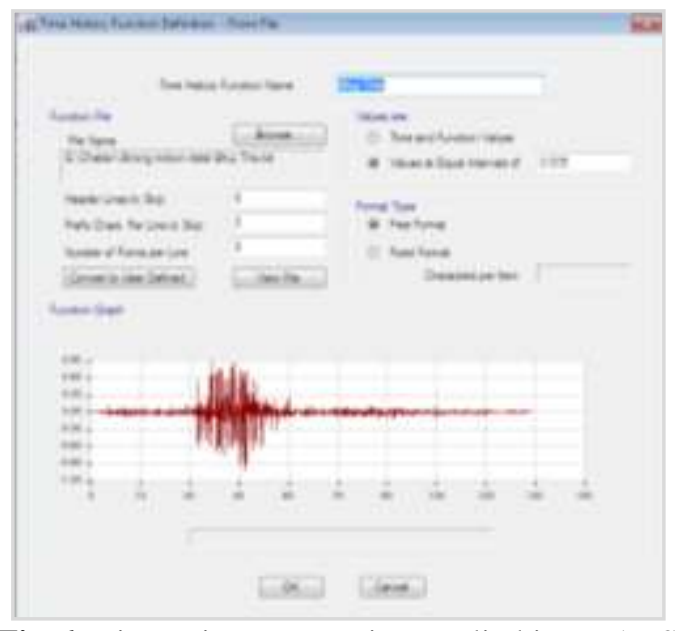

Fig-6: Time History Function applied in ETABS

The ETABS model of six story shear building is analyzed by Equivalent Static Method[11] and Linear Modal Time History Method[12] to obtain base shear values and displacement response values of each floor.

\section{RESULTS AND DISCUSSIONS}

The MDOF system analyzed by theoretical method is compared with ETABS model analysis thus discussed in this section of the study.

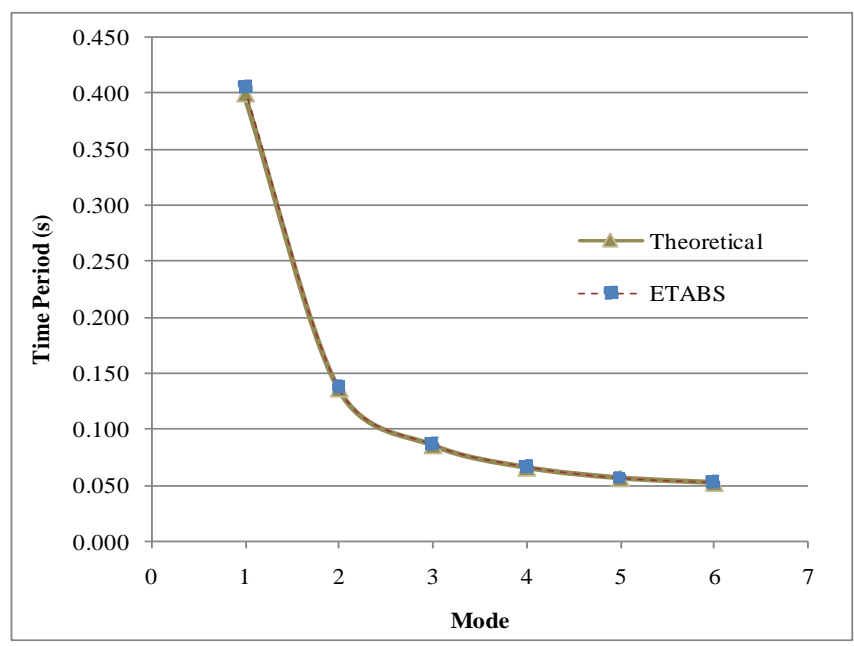

Fig-7: Modal Time Periods

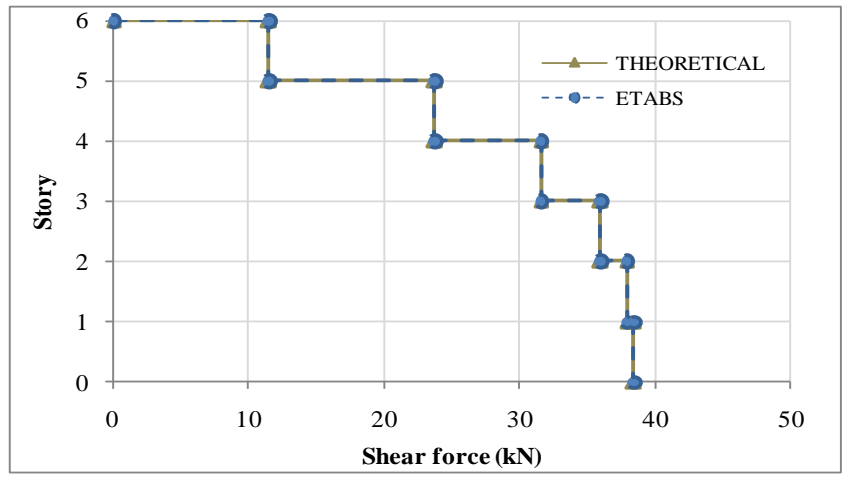

Fig-8: Story Shear Force by Equivalent Static Method 


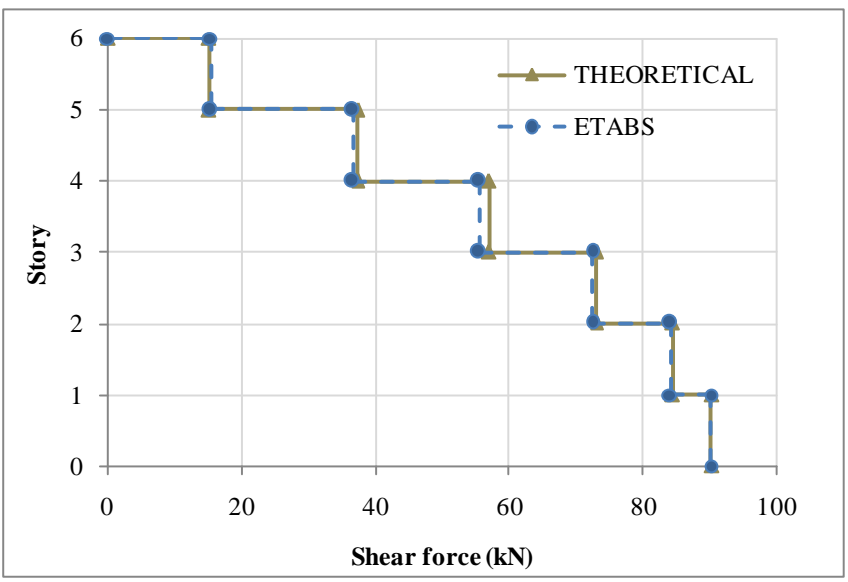

Fig-9: Story Shear Force by Time History Analysis

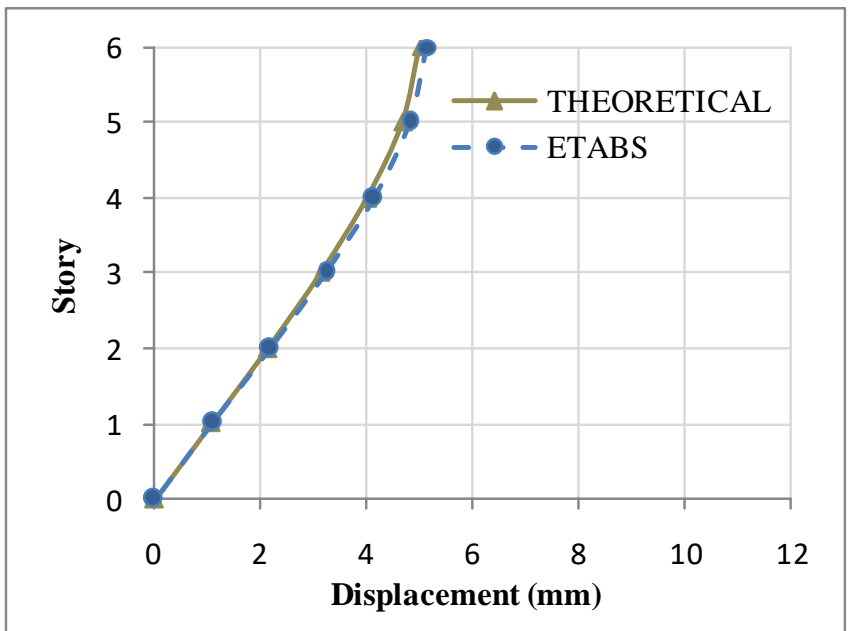

Fig-10: Max Top Story Displacement by Equivalent Static Method

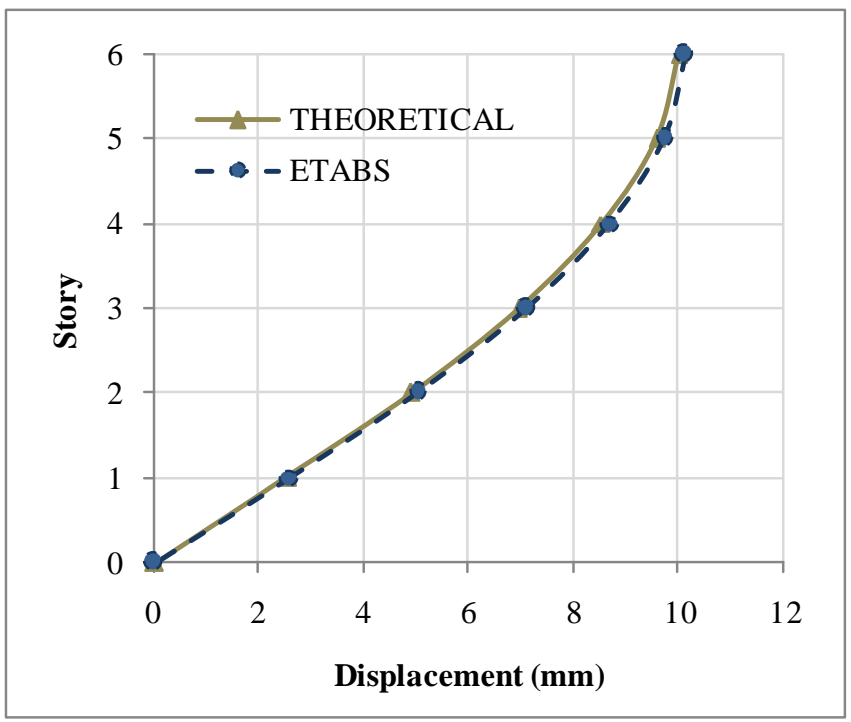

Fig-11: Max Top Story Displacement by Time History Analysis

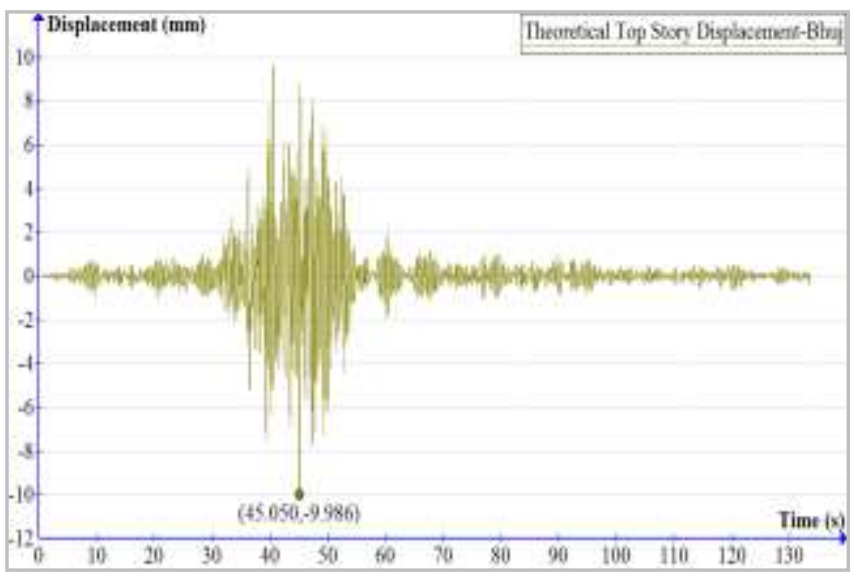

Fig-12: Top Story Displacement Time History by Theoretical Analysis

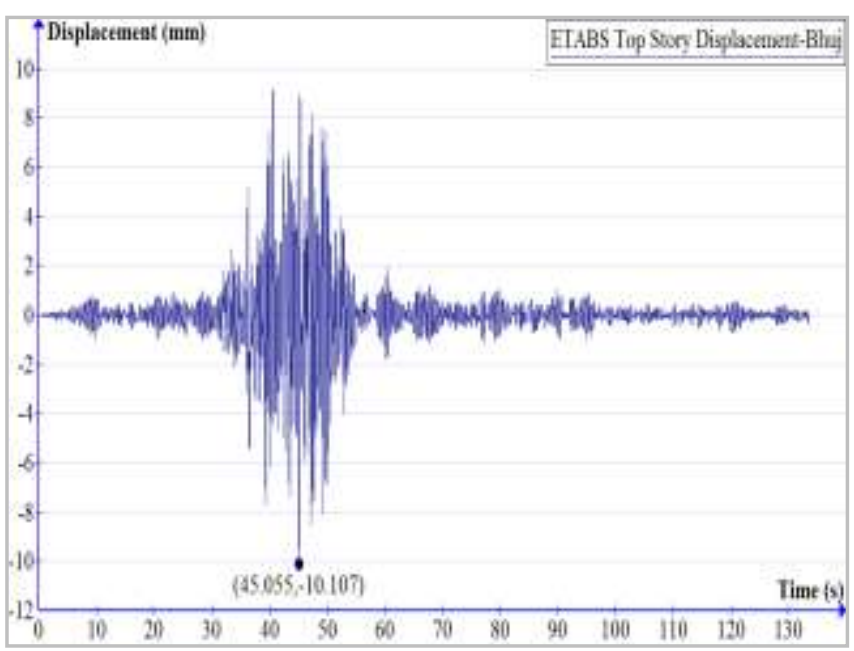

Fig-13: Top Story Displacement Time History by ETABS

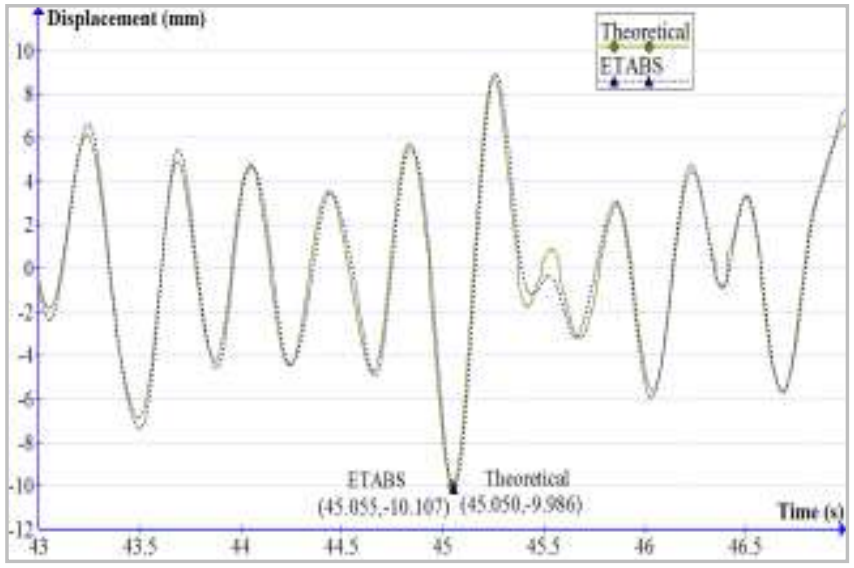

Fig-14: Top Story Displacement Time History Comparison

The time periods of each mode are obtained with the help of eigen values identified by solving characteristic equation. These time periods are compared with modal time periods obtained from analyzing the same geometry building in ETABS software. The comparison is shown in fig.7 that indicates good conformity in the modal time periods with at variation of 1 to $2 \%$. 
The mode shapes obtained from ETABS are compared with theoretical mode shapes by normalizing at the top floor for each mode. It is observed that the mode shapes obtained from ETABS are exactly matching with the theoretically calculated mode shapes.

The building system is analyzed using Equivalent Static Method theoretically and using ETABS software and the story shear force results are observed to be same in both the cases. The corresponding graph is shown in fig. 8 .

Story Shear forces obtained by linear modal time history analysis of the six story shear building performed using Newmark's Linear Acceleration Method is compared with ETABS results as shown in fig.9. The story shear forces due to applied ground excitation by theoretical and ETABS time history analysis vary by $2 \%$.

The response of building in terms of story displacement is also compared in fig. 10 by Equivalent Static Method. There is approximately $3 \%$ of variation in the displacement of floors.

Maximum story displacement of the six story shear building subjected to ground excitation is shown in fig. 11. The variation in the results of the floor displacement response is 1 to $3 \%$. The maximum top floor displacement time history is obtained from theoretical analysis as shown in fig. 12 and using ETABS as indicated in fig. 13. This top floor displacement response is compared for theoretical and ETABS analysis as shown in fig. 14 which indicates that the peak top story displacement response is occurring at time instance of $45.05 \mathrm{sec}$ in theoretical and at $45.055 \mathrm{sec}$ in ETABS analysis.

\section{CONCLUSION}

- The modal time periods and vibrations mode shapes shown by ETABS software are almost same as obtained by theoretical calculations.

- $\quad$ The results obtained by ETABS software are acceptably matching with the results obtained theoretical analysis using Newmark's Method for Equivalent Static Method of analysis.

- Displacement of the floors identified using ETABS and theoretical approach are in good agreement with each other for Equivalent Static Method.

- The time history analysis performed using the algorithm based on theoretical time stepping method called Newmark's Linear Acceleration Method is compared with the linear modal time history analysis performed using ETABS software. The obtained base shear values from both theoretical and ETABS analyses are in good conformity with each other.

- Response of building in terms of displacement obtained using ETABS software is in good agreement with the displacement response by theoretical analysis when the Newmark's Method fulfills stability and convergence condition.

\section{ACKNOWLEDGEMENT}

Authors are grateful to the Civil Engineering Department of Dr. Vithalrao Vikhe Patil College of Engineering Ahmednagar for motivation and supporting with laboratory facility in this study.

\section{REFERENCES}

[1] S. K. Jain, "Indian Earthquakes: An Overview," Indian Concr. J., vol. 72, no. 11, 1998.

[2] R. Bilham, "Earthquakes in India and the Himalaya: Tectonics, geodesy and history," Ann. Geophys., vol. 47, no. 2-3, pp. 839-858, 2004.

[3] R. N. Iyengar, D. Sharma, and J. M. Siddiqui, "Earthquake history of India in medieval times," Indian J. Hist. Sci., vol. 34, no. 3, pp. 181-237, 1999.

[4] H. Mittal, A. Kumar, and R. Ramhmachhuani, "Indian National Strong Motion Instrumentation Network and Site Characterization of Its Stations," Int. J. Geosci., vol. 3, no. 6, pp. 1151-1167, 2012.

[5] R. Archuleta, J. Steidl, and M. Squibb, "The COSMOS Virtual Data Center," in 13 th World Conference on Earthquake Engineering, 2004, no. Paper No. 1566.

[6] D. Costa, "Standard Methods for Seismic Analyses," BYG.DTU Technical University of Denmark, 2003.

[7] J. Carr, "Dynamic Analysis of Structures," Bulletin of The New Zealand National Society for Earthquake Engineering, vol. 27, no. 2, pp. 129-146, 1994.

[8] BIS, "Criteria for Earthquake Resistant Design of Structures," Bureau of Indian Standards, India, IS 1893 Part 1, 2016.

[9] N. M. Newmark, "A Method of Computation for Structural Dynamics,” J. Eng. Mech., vol. 85, no. 7, pp. 67-94, 1959.

[10] K. Chopra, Dynamics of Structures: Theory and Applications to Earthquake Engineering. New Delhi: Dorling Kindersley (India) Pvt. Ltd., 2006.

[11] "ETABS Lateral Loads Manual." Computers \& Structures, 2016.

[12] P. R. Vaidya, "ETABS- Time History Analysis." [Online]. Available: www.academia.edu. [Accessed: 14-Nov-2017]. 